\title{
10 health stories that mattered: June 28-July 4
}

- Health Canada is seeking public feedback until Aug. 28 about proposed tamper-resistant regulations for controlled-release oxycodone and other drugs considered at high risk for abuse. Under the proposed regulations, a "tamper-resistant formulation" would have to meet several criteria, such as inducing an unpleasant or aversive effect when manipulated for misuse.

- The public drug plans of Quebec and Ontario have the highest coverage rates for new drugs, and the plans for Manitoba and Alberta have the lowest rates, reports the Canadian Health Policy Institute. Overall, there was full or partial coverage under public drug plans for only $23.1 \%$ of the 412 new drugs approved by Health Canada from 2004-12 as of Dec. 1, 2013.

- Canada's military should conduct "rigorous mental health screenings" of new recruits, recommends a report from the Standing Committee on National Defence. Other recommendations include expanding government research into the presusceptibility of operational stress injuries and enhancing the education on mental health issues provided to military families.

- Dr. Richard Cruess was awarded a Companion of the Order of Canada for his pioneering work in the field of medical professionalism. The new Officers of the Order of Canada include Dr. Philip Branton, who was rewarded for his leadership in developing a national cancer research framework. Dr. Guy Breton received a Member of the Order of Canada for his contributions to medical radiology. Many other health professionals were also recognized for their contributions to medicine.

- Health Canada blamed technical limitations for preventing the public release of information about off-label drug side-effects, including reports of deaths, heart attacks, strokes, birth defects and organ failures. In a statement to the Toronto Star, a spokesperson said the regulator is upgrading its systems, but did not provide a timeline for when the missing reports will be publicly available.

- Canadian families will pay on average $\$ 3592$ to $\$ 11786$ in taxes for public health care in 2014, depending on the size of their family, reports the conservative think-tank Fraser Institute. Using data from Statistics Canada and the Canadian Institute for Health Information, the institute estimates the cost of public health care for the average Canadian family increased 1.5 faster than average income over the last decade.

- Local, low-emitting polluters like auto shops and corner laundries cause at least 120 deaths in Toronto each year, reports Toronto Public Health. The 2014 ChemTRAC study - the first in Canada to measure the impact of neighbourhood polluters - attributes 120 premature deaths and 200 hospitalizations for heart and lung disease to air pollution, while deaths related to cancer-causing tox- ins like tetrachloroethylene, a liquid used in dry cleaning, could not be proven directly and were not counted.

- New financial statements for Alberta Health Services reveal a number of large payments to departed executives, including one former vicepresident who took home more than $\$ 1.7$ million in severance and pension in 2013-14. The documents also reveal upheaval in the health authority's top ranks, including the dismissal of five vice-presidents, who together shared about \$2.4 million in severance.

- The World Health Organization is rolling out a new strategy to reduce tuberculosis in 33 wealthy countries with low-levels of the disease, including Canada. The strategy will be used to pilot approaches that could be transferred to poorer nations. It involves broader screening for both active and latent infections in high-risk groups, funding high-quality health services, and investing in new drugs, vaccines and diagnostic tests.

- More than a thousand visitors to a Saskatchewan resort motel may have been exposed to hepatitis A, warn health officials. They're advising anyone who visited the Mainstay Inn Motel and Restaurant near Riverhurst between June 1 and 22 to contact a health professional to have their vaccination records checked; unvaccinated visitors may need to be immunized. — Lauren Vogel, CMAJ

CMAJ 2014. DOI:10.1503/cmaj.109-4842 